\title{
CORRIGENDUM
}

\section{Targeting tumor gene by shRNA-expressing Salmonella-mediated RNAi}

\author{
H Guo ${ }^{1,2}$, J Zhang ${ }^{1,2}, \mathrm{C} \mathrm{Inal}^{1}$, T Nguyen ${ }^{1}$, JH Fruehauf ${ }^{1}$, AC Keates ${ }^{1}, \mathrm{CJ} \mathrm{Li}^{1}$ \\ ${ }^{1}$ Skip Ackerman Center for Molecular Therapeutics, Division of Gastroenterology, Beth Israel Deaconess Medical Center, Harvard Medical School, Boston, MA, USA \\ Correspondence: Dr H Guo, Skip Ackeman Center for Molecular Therapeutics, Division of Gastroenterology, Beth Israel Deaconess Medical Center, Harvard Medical School, \\ Boston, MA, USA. E-mail: guohn2000@gmail.com; CJ Li, E-mail: cli@bidmc.harvard.edu \\ ${ }^{2}$ These authors contributed equally to this work.
}

Gene Therapy (2011) 18, 106; doi:10.1038/gt.2010.154; published online 11 November 2010

Correction to: Gene Therapy advance online publication, 2 September 2010; doi:10.1038/gt.2010.112

Since the publication of the article the Authors and Editors have determined that a number of contributing authors had been omitted from the list of authors. The correct list of authors is shown above.
The Authors also omitted acknowledgement of grant support. The acknowledgements section should read:

This study was supported by the Skip Ackerman Medical Foundation, a Global Research Laboratory Award from the Ministry of Education, Science and Technology of Korea, and Scientist Exchange Program grants from the National Cancer Institute.

The Authors apologize for these errors. 